\title{
VARIA
}

\author{
ALBORAIQUE. UN DATO ICONOGRÁFICO
}

El odio religioso es una característica de la Historia de España, que comparte con las restantes naciones europeas. La implantación en Castilla, a instancias de los Reyes Católicos, del Tribunal del Santo Oficio de la Inquisición, creado por bula de Sixto IV de 1 de noviembre de 1478, se considera como el punto de partida de la institucionalización del odio religioso y la intolerancia, cuyas secuelas llegan a nuestros días. El Santo Oficio será una de las estructuras más eficaces de la España Moderna, hasta su desaparición definitiva en 1820 durante el Trienio Liberal. Los monarcas españoles, todos sin excepción, desde los Reyes Católicos hasta Fernando VII, apoyarán y se valdrán de la Inquisición para conseguir sus objetivos, siendo la Iglesia y la Monarquía los dos máximos beneficiarios de ese colosal testimonio de la infamia.

Desde el primer proceso de Llerena de 17 de septiembre de 1479, por el que fueron quemados vivos por judaizantes Garci Fernández Valencí y Pedro Franco de Villarreal, y condenadas a otras penas menores Isabel García y su hija Mayor, con secuestro de bienes y destrucción de sus casas ${ }^{1}$, hasta el momento de su extinción tras el pronunciamiento de Riego, el Santo Oficio fue una máquina implacable y demoledora contra toda disidencia religiosa y moral, y su pavoroso sistema de obrar, desde el más absoluto sigilo al más atronador espectáculo de los autos de fe, a los que asistían los reyes a veces, justifica que atraiga todas las miradas, y que su brillo siniestro oscurezca otros rasgos anteriores y contemporáneos del odio religioso en España.

El arraigo del fanatismo, la intolerancia y el odio religioso en nuestra nación viene de lejos, siendo gran estímulo para ello los ocho siglos de guerra entre cristianos y musulmanes en todos los rincones de la península, a lo que hay que sumar la constante ojeriza habida de siempre entre cristianos y judíos. El final de la Reconquista en 1492 no aminoró el enfrentamiento. Los judíos fueron expulsados ese mismo año de España, y la guerra contra el moro prosiguió en Africa y en el mar, apareciendo la piratería y el golpe de mano como un mal endémico por toda la costa mediterránea.

Pero los enfrentamientos entre los cristianos y judíos y los cristianos y moros fueron muy distintos, y aunque las consecuencias al final serán las mismas, los procesos fueron por completo

\footnotetext{
${ }^{1}$ F. R. de C., «Inquisición de Castilla». RABM, 1871, págs. 93-94.
} 
diferentes. El problema judío tuvo un punto explosivo en 1391, con el asalto y destrucción de las aljamas de España, y el bautismo a la fuerza de muchos de los supervivientes si no querían morir. Con ello apareció el problema converso, que se arrastrará durante siglos, y será el causante directo de la aparición del Santo Oficio de la Inquisición.

Si el odio entre judíos y cristianos era implacable, y cultivado a diario desde hacía siglos en sinagogas e iglesias; con respecto a los conversos, el encono fue todavía mayor por lo que respecta a los cristianos, pues en ellos veían a un enemigo dentro de la comunidad. Pero combatirlos era muy difícil, pues a todos los efectos eran cristianos. A lo largo del siglo XV aparecerán diversos escritos donde los fustigan, diciendo que no son cristianos, que su conversión es falsa, que siguen siendo judíos, y por ello, y por hipocresía y falsedad, deben ser castigados.

Acaso el ataque más descomunal y despiadado sea un opúsculo llamado Alboraique, de anónimo autor e incierta fecha. Suele datarse a fines del siglo XV, siendo generalmente aceptada la fecha de $1488^{2}$; editándose, según unos hacia 1488, para otros en 1545, y recientemente Yarza sostiene que se publica a finales del siglo XVI. Del autor nada sabemos. Se ha atribuído a Alonso de Orozco, y como tal es recogido, aunque como atribución dudosa, por Palau y Dulcet ${ }^{3}$. Curiosamente, de este opúsculo se conservan manuscritos, destacando el 17.891 de la Biblioteca Nacional de Madrid, en el cual se encuentra el Alboraique entre los folios 233 y 264, y de él se hará la edición más reciente de este texto ${ }^{4}$. Consta la existencia de otro manuscrito en la biblioteca del Duque de Alba, aunque hoy no sabemos donde para ${ }^{5}$. Pero además, el Alboraique se editó; Salvá lo tenía en su famosa Biblioteca, y deduce del texto y del modo en que está compuesto el libro, que es una obra impresa en Sevilla en 1545, y salida de la oficina de J. Cromberger $^{6}$. El único ejemplar de libro impreso que conocemos, es el que se custodia en la Real Biblioteca del Escorial ${ }^{7}$.

Quien escribe el Alboraique es súbdito de alguno de los reinos de la Corona de Castilla, formado en la escolástica, la dialéctica y la refutación, y un experto conocedor de la pugna con los judíos y el problema converso, lo que da lugar a sospechar que fuese de estirpe conversa, lo que se refuerza por el conocimiento que tiene de expresiones hebreas muy concretas. Dice que la palabra judaizante se empleó por primera vez en Llerena, y se refería a los nuevos convertidos del judaísmo al cristianismo tras las matanzas y destrucción de las aljamas de 1391, a la que llama guerra que se hizo en toda España; dichos conversos fueron bautizados a la fuerza ${ }^{8}$. Este tipo

${ }^{2}$ F. Pérez Aguado, «Los alboraicos». La Ciudad de Dios. XLI, 1896, págs. 120-125. N. López Martínez, Los judaizantes castellanos y la Inquisición en tiempo de Isabel la Católica, págs. 53-54, Burgos, 1954. J. Yarza Luaces, Los Reyes Católicos. Paisaje artístico de una monarquía, págs. 33 y 396, Madrid, 1993.

3 A. Palau y Dulcet, Manual del librero hispanoamericano. Bibliografía general española e hispanoamericana desde la invención de la imprenta hasta nuestros tiempos con el valor comercial de los impresos descritos. Tomo Duodécimo. Orozco-Pereyro. 204418-218986, pág. 3, núm. 204442. Segunda edición corregida y aumentada, Barcelona, 1959.

${ }^{4}$ N. López Martínez, Los judaizantes castellanos, págs. 391-404.

5 Archivo y Biblioteca Zabálburu. Carpeta 49. Prospecto en general de los libros y papeles manuscritos que tiene en su Bibliotheca el Excelentissimo Señor Marques de Astorga Conde Duque mi señor Cavallerizo mayor del Principe N. S. Año 1784.

En el Cathalogo de los libros, ms. de la libreria de el Exmo. Señor Duque de Alba mi Señor.

Núm. 353. Un tratado llamado el Alvoraique contra los Judios conversos.

${ }^{6}$ P. Salvá y Mallén, Catálogo de la Biblioteca de Salvá. 2 vols. Valencia, 1872.

7 Alborayque. Biblioteca de San Lorenzo el Real del Escorial (B.S.L.E.) 53-I-37. Este opúsculo, sin lugar, ni año, de formato en cuarto, letra gótica minúscula, con sólo dos capitales adornadas, y las demás sin ornato, está encabezado por una xilografía con la representación del alboraique. Las citas se sacan del texto escurialense.

${ }^{8}$ En la villa de Lerena en la prouincia de Leon: fue puesto a los conuertedizos neofitos judayzantes. Conuiene a saber a los conuersos que se tornaron cristianos agora ha setenta años y mas: y de la guerra que estonce (sic, por entonces) se fizo en toda España por muerte de espada: conuiene a saber destruycion en las aljamas de los judios. E los que quedaron biuos por la mayor parte los baptizaron por fuerça. 
de conversos recientes, a los que llama alboraicos y les acusa de todas las maldades y vicios imaginables, son fundamentalmente andaluces, murcianos y del reino de Toledo, y no deben confundirse con los buenos y honrados convertidos de la zona de la Meseta Norte, donde prácticamente no existe tal estirpe 9 .

Por testimonios contenidos dentro del texto, puede datarse razonablemente en la década de 1470 y posiblemente antes de la muerte de Enrique IV ${ }^{10}$. Si no nos equivocamos en nuestra hipótesis cronológica, nos hallamos ante un producto que es anterior a la instauración del Santo Oficio, y un exponente meridiano del odio religioso que había en España en el siglo xv. El autor de este libelo, que conoce a la perfección la situación de los conversos con respecto a la comunidad judía ${ }^{11}$, dice de ellos que comparten rasgos moros, judíos y cristianos, y no son ninguna de las tres cosas; por ello, para vituperarlos, les llama alboraicos, nombre que no aparece en la Biblia, pero sí en el Corán, siendo el alboraique la montura con la que Mahoma subió al cielo $^{12}$. Una vez que los ha desarraigado de cualquiera de los tres grupos religiosos, los lanza

9 Otros [alboraicos] son de los tiempos modernos de quien el p[ro]logo haze mencion: et se baptizaron por fuerça: et estos no son cristianos. E esto de deuen auer por reproche: los buenos de los conuersos de Castilla antes por honrra: que si ouiessen de ser juzgados con los conuersos andaluzes y aun tholedanos: todos serian condenados por malos hereges: lo qual no es assi mas lo contrario. Ca assi como en Castilla Vieja Burgos Palencia Valladolid Çamora Leon etc. apenas fallaran dellos de los conuersos naturales hereges ningunos. Assi en el reyno de Tholedo et Murcia et Andaluzia Estremadura apenas fallaredes dellos ningunos cristianos fieles: lo qual es notorio en toda España. Aunque la gran heregia destos quiere traer causa de durar en los otros de Castilla arriba.....

${ }^{10}$ La primera referencia para la datación del texto, es la alusión a la caída de Constantinopla en 1453: «El pecado por que fue destruyda Costantinopla: por la usança con los moros dexo por el presente: pues por la pena podeys conoscer el delito». A partir de ahí, existen otras referencias que empujan al texto hacia la década de los setenta. Una es la alusión a Diego Arias en las Coplas de Mingo Revulgo, que suelen datarse en 1464: «E por esto se dixo del malauenturado Diego Arias en las coplas de Mingo Rebulgo quando asso una cabeça et dexola bien estrujada». Efectivamente, el texto hace referencia a la siguiente copla de Mingo Revulgo: Trae un lobo carnicero / Por medio de las manadas: / Porque sigue sus pisadas / Dice a todos ques carnero. / Suéltale de la majada, / Desque da una ondeada / En tal hora lo compieça / Que si ase una cabeça / Déxala bien estrujada. / Fernando del Pulgar, Letras. Glosas a Las Coplas de Mingo Revulgo. Edición y notas de J. Domínguez Bordona, pág. 164, Madrid, 1958. La otra referencia cronológica se recoge en la nota 8 de este trabajo, cuando dice que los asaltos, matanzas y destrucciones de las aljamas de 1391 ocurrieron «agora ha setenta años y más», lo que nos remite, como mínimo, al año 1461 y siguientes, y muy concordante con las Coplas. Pero hay una referencia todavía más concreta, que alude, por una parte a Herodes, y, por otra, a la destrucción de Jerusalén en el año 70 después de Cristo: «Jacob dixo: No se quitara el caudillo del tribu de Juda: ni sera quitado el su señorio: fasta que venga el que ha de venir: que es el messias: segun dize el caldeo. pues el señorio es quitado mill et quatrocientos años ha el mas. que pideron rey: et reyno Herodes: et nunca mas ovieron vara de justicia: ergo mill et quatrocientos años ha que vino el verdadero messias». La otra referencia es la siguiente: «Concluyo si los metales son muchos en los alboraycos segund la carne. quanto mas de metales de tantas heregias como han et tienen de tiempos antiguos..., et despues de las heregias que tienen de los infieles padres suyos que han venido mil et quatrocientos años ha: et mas captiuos ciegos entre los cristianos et moros». Si es correcta nuestra interpretación, tendríamos la fecha de 1470. Finalmente hay otra referencia, que no hemos logrado localizar, y que de serla, daría la fecha definitiva de la datación del texto, dice así: «E ahe esperiencia probada que los que iban al turco et quemaron en Valencia de Aragon este año: et los que fuyeron et los que restaron desta gente iban a ayudar al turco por derramar sangre de cristianos».

11 E desto tomaron entre si un sobrenombre en ebrayco Hanuzyn, que quiere dezir forçados. E si alguno se torna cristiano de grado: et guarda la ley cristiana. llamanle Messumad. en ebrayco. que quiere dezir reboluedor: que los rebuelue con los cristianos. E si alguno deste linaje llega a algund lugar donde ay aquesta mala generacion, preguntanle eres Anus id est cristiano por fuerça: o Messumad. cristiano por voluntad. E si responde Anus soy danle dadiuas: et honrranle. E si dize Mesumad. no le fablan mas.

${ }_{12}$ Assi como los destas partes a bueltas de otros dessa Andaluzía et de España. sean Hanuzyn cristianos porque mas no pueden fazer. Esto es en el nombre: ca no en las obras: guardando el sabad: et otras cerimonias judaycas rezando por los libros de judios. Empero porque ellos tienen la circuncision como moros: y el sabado como judios: et el nombre solo de cristianos. E ni sean moros ni juidios ni cristianos: aun por la voluntad judios: pero no guardan al talmud: ni las cerimonias todas de judios: ni menos la ley cristiana. E por esto les fue puesto este sobrenombre por mayor vituperio: conuiene a saber. Alboraycos: a todos ellos. et a uno solo. Alborayco. E yo buscando la ley vieja y nueva este nombre no falle: ni en glosas de la escriptura: pero fallelo en el alcoran. Ca Mahomad caudillo de los moros fingio que Hala embio del cielo a lo llamar con el angel Gabriel. E que para yr alla le traxo un animal que assi se llamaua alborayque: en que fuesse cauallero 

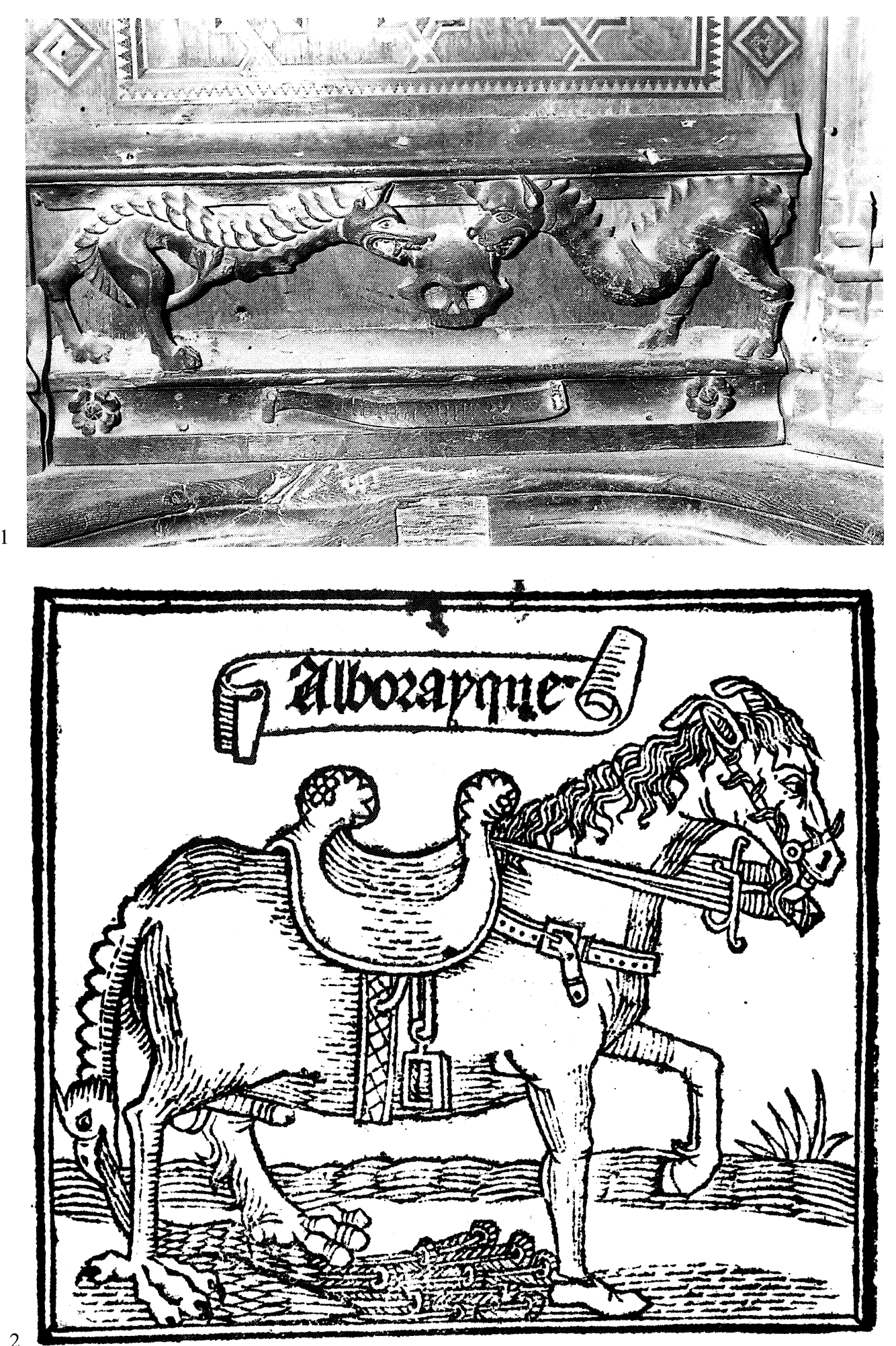

FIG. 1. Nufro Sánchez, Relieve del Alboraique, Sillería de coro. Sevilla. Catedral.

FIG. 2. Alboraique, xilografía en el «Libro del Alborayque». El Escorial (Madrid), Biblioteca del Monasterio. 
hacia la falsedad más absoluta, como el mismo alboraique, que ni existe en el texto del Viejo y Nuevo Testamento, es decir, la Ley, ni en el tradicional De natura animalium ${ }^{13}$.

Seguidamente enumera las veinte características de la mítica montura de Mahoma, las coteja y analiza con el comportamiento de los conversos, y concluye en cada una de las comparaciones, que son idénticos. Ese discurso es de una enorme plasticidad, siendo factible trasladar las palabras a imágenes. Significativamente tal paso se dio en Sevilla, tallándose el alboraique en la sillería de coro de la Catedral en 1478 por Nufro Sánchez ${ }^{14}$. El artífice representa esta mítica montura en una escena, en la que se le efigia como dos monstruos simétricos que muerden una misma calavera. Isabel Mateo ha puesto en contacto esta representación con el texto del Alboraique, y aprecia en las figuras algunas características citadas por el libelo, concretamente ocho. Puede decirse que es así en los rasgos - boca, ojos, orejas, etc. -, sin embargo el tallista imaginó el alboraique más como una sierpe que como una montura similar a los équidos; su idea es más bien la de un dragón monstruoso y diabólico, que la de una criatura «menor que cauallo et mayor que mulo» (Fig. 1).

Representar seres nuevos, inventar imágenes es una de las mayores dificultades del ser humano, por ello engrosar los repertorios figurativos resulta costosísimo y generalmente reservado a mentes privilegiadas. Los artistas nunca trabajan desde la nada, sino a partir de las formas heredadas y conocidas, lo que explica el modo de concebir al alboraique en la sillería de coro de la Catedral de Sevilla, pero, a su vez, la novedad de esa representación y lo poco preciso de sus rasgos, forzó al escultor a tener que poner su nombre debajo, escrito en una cartela, para que comprendiese el espectador lo que estaba viendo. Incluso así, nos resulta harto enigmático el significado de la escena sevillana de dos alboraiques mordiendo una calavera.

Ignoramos si esta forma plástica de representar a los conversos de modo infamante tuvo fortuna y se extendió por España; pero lo que sí tuvo larga vida fue el opúsculo donde se les llamaba alboraicos. La creación del Santo Oficio en 1478, y la expulsión de los judíos en 1492 incrementó todavía más el problema converso, que se convirtió en una obsesión constante durante dos siglos. Con este ambiente se justifica que el Alboraique fuera editado en el siglo XVI.

Si la hipótesis de Salvá es cierta, y el Alboraique se edita en Sevilla en 1545, nuevamente se produciría una relación entre el libelo antijudío y la ciudad andaluza. En cuanto al contenido textual, no hay diferencias con respecto a los manuscritos conocidos hoy; lo que tiene de nuevo es la ilustración del comienzo: una xilografía que intenta plasmar la efigie del alboraique, poniendo en una imagen el complejo texto con sus veinte características (Fig. 2). Esta representación no tiene nada que ver con la de Nufro Sánchez de 1478, es mucho más literal que la talla escultórica, pero también menos terrible.

El artífice ha concebido al alboraique como una montura del tipo équido, e incluso la apostura es la consagrada en aquellos años por la tradición italiana. A partir del caballo, el animal se va transformando. Tiene la boca de lobo ${ }^{15}$, aspecto muy resaltado en la sillería coral sevillana y en

${ }^{13}$ El qual animal es menor que cauallo et mayor que mulo. E como no sea ninguno de los animales de natura que en la ley se falla: ni en el libro de natura animalium. segund las señales que en el dicho alcoran: et en glosas suyas de los sabios de los moros se falla. Por ende como tal animal no sea en ley de escriptura: ni en ley de gracia. Assi se concluye que ellos ni son judios ni cristianos: ni menos moros. Ca la seta de los moros no la creen: ni menos la de los cristianos que se llaman et no la creen. E las señales que dizen los moros que el alborayque auia nombradas todas aqui por sus significaciones: estas mesmas han los neofitos por condiciones.

14 I. Mateo Gómez, «Alegorías de los conversos o alboraiques y del amor en Sevilla y Barcelona». AEA, 199, 1977, págs. 316-320. Publica además la fotografía con la representación de los alboraiques de la sillería coral de la Catedral de Sevilla. Queremos agradecerle públicamente que nos facilitara la reproducción sevillana aquí recogida.

${ }^{15}$ Lo primero el alborayque tenia boca de lobo. Esto es que estos alboraycos son ypocritas et falsos prophetas llamandose cristianos et no lo son... Ca siendo malos et hereges fingen de cristianos: et son lobos: veyendo todos que por sus obras son lobos. 
absoluto resuelto en la xilografía; la cabeza de caballo está muy bien trazada ${ }^{16}$, así como la forma humana de sus ojos ${ }^{17} \mathrm{y}$ las orejas de perro lebrel ${ }^{18}$; el cuello es de hacanea con bellas crines, tratadas de modo completamente distinto a la especie de cresta de los alboraiques de Nufro ${ }^{19}$; el cuerpo de buey no está bien resuelto, sobre todo por la parte delantera ${ }^{20}$; la cola de serpiente ${ }^{21}$, acabada en cabeza de grulla ${ }^{22}$, de la que salen plumas de pavo real ${ }^{23}$ son explícitas; lo mismo ocurre con la cuatro patas, todas distintas: una humana con calzas y zapato ${ }^{24}$, la otra de caballo herrada ${ }^{25}$, la

${ }^{16}$ La ii. habia el alborayque rostro de caballo. los caballos por su ligereza et valentia entre los otros animales son escogidos para matarse las gentes et derramar sus sangres. E assi esta maldita generacion fueron et son ligeros. et se fizieron fuertes para matar los prophetas a Ysayas a Zacharias et a los apostoles et martyres. et corrieron a derramar la sangre de Iesu Cristo.

${ }^{17}$ La tercera. habia ojos de hombre aquel alborayque assi los neofitos alboraycos miran como hombres humanos piadosos falagueros: et ellos son inhumanos et crueles. Habia el alborayque ojos de hombre pero no era hombre. E assi estos alboraycos parescen hombres en la parescencia: et son diablos en las obras.

${ }_{18}$ La quarta condicion del alborayque habia orejas de perro lebrel. assi estos alboraycos son propios lebreles grandes perros son: y esto es verdad que assi como el perro no ha vergüença de su señor de fazer sus faziendas delante del: ni delante de las otras gentes. Assi estos hombres perros no han vergüença de Dios: ni aun del rey ni de las gentes de fazer sus faziendas: ni cerimonias judaicas: ni de decir sus herejias ni mentiras. E otrosi como el perro torna el vomito a comer lo que bosso. assi estos canes tornan al sabad: et adafina et caçuelas et circuncision, et cerimonias que usaron ya quando se baptizaron..... Yten el can con rabia de su dueño traba. Assi estos perros mordieron a su señor con la rabia de la envidia diabolica.

${ }^{19}$ La quinta condicion que habia cuello de hacanea con crines el alborayque assi estos alboraycos como la hacanea no es para trabajar por sierras ni por tierras asperas: ni se aprovechan della salvo para andar por plaças et ruas. Assi estos alboraycos no son para guerreros contra los enemigos de la fe: ni nos servimos el pueblo cristiano dellos en los actos de guerra: ni sirven en los trabajos asperos de labradores: mas como hacaneas andan por la plaça que es la corte: et por las calles de los cristianos a engañar las gentes que se figuran por las crines del alborayque por muchos caminos de engañarnos. Afeitando aquellos engaños encrinandolos como crines de hacaneas.

Covarrubias define así la hacanea: «la que es preciada, cavalleria de damas o de principes». S. de Covarrubias Orozco, Tesoro de la Lengua Castellana o Española. Madrid-México, 1984.

${ }^{20} \mathrm{La}$ vi condicion cuerpo de fechura de buey habia el alborayque. Assi estos alboraycos han cuerpo de buey finchiendo sus vientres et cilleros de las dehesas mas a furto mudando el pelo son luzios..... sus ovejas gruesas: sus fijas pintadas: palacios encalados como los templos: mas su diestra toda es de maldad et de traicion. E dizen ellos que son bienaventurado pueblo por estas cosas que tienen: et esto no es verdad. Ca bienaventurado es el pueblo que tiene a Dios por señor et no tiene fe ni creencia con las riquezas temporales.

${ }^{21}$ La vii condicion que habia el alborayque: cola de serpiente asechando derramando muchas herejias rastrando por la tierra.

${ }^{22}$ La viii condicion es: en cabo de la cola una cabeça de grulla. Esta condicion es en los alboraycos que assi como las grullas vienen una delante et las otras andan tras ella: dize la delantera gru gru. et siguen las otras aquella. Assi no ay mas de un alborayque en el mundo: que si en uno tocaredes todos se sienten et dizen gru gru. E todos venieron por un camino desterrados por infieles et sus aguelos et aca dauan las semientes de las palabras de Dios arrancando las que no dan fruto de vida: et despues tornaronse hereges: et como las grullas vienen a grand miedo entre nos: et se velan de noche. assi esta gente biuen a grand miedo entre nos. E como apena podedes matar una grulla: ca ponen sobre si grand remedio de velas y guardas. Assi apenas por justicia podedes matar un alborayque que ponen sobre si guardas remedios de cohechos y monedas. E assi como las grullas vienen en tiempo frio et despues quieren tornar a sus tierras: et recebimos aca daños dellas: asi venieron ellos captiuos et recebimos grandes daños dellos: et todavia querrian tornar a Judea.

${ }^{23}$ La ix en cabo de la cola: auia una figura de pavon: assi los alboraycos son pomposos vanagloriosos: et llenos de toda vanidad et locura deste mundo. E mirandose como el pavon quando faze la rueda. E desque mira los pies que ha feos et negros: esmortesce e desmaya et cae amortescido: et pierde todo el coraçon que ha. Assi los alboraycos puesto que sean ricos e generosos en dignidades puestos en la plaça para ser mirados como el pavon: desque veen el vil linaje de donde vienen maldito despreciado de Dios ey de cristianos et moros pierden el coraçon et desmayan.

${ }^{24} \mathrm{La} \mathrm{x}$ avia un braço de pierna de ombre con calça galante et pie calçado. Esto es notado por la grand soberbia loçania locura que los alboraycos han de querer pisar et sojuzgar los cristianos de la tierra donde biuen. E porque esta significacion es muy notoria abreuiola. E por esto Dios ensalça los cristianos sobre ellos: et a ellos abate.

${ }^{25}$ La xi. otro braço de pierna de caballo con ferradura.

La xi otro braço de caballo con ferradura. esto es que los alboraycos al cristiano que toman sojuzgado en deuda: o en qualquier subjecion: estrujanlo como uvas en el lagar et quebrantanlo. E bien como se duele ombre del cauallo si le pone la mano sobre el pie. Assi se dueles los cristianos de las injurias et malos estrujamientos et robos dellos. E por esto se dixo del malauenturado Diego Arias en las coplas de Mingo Rebulgo quando asso una cabeça et dexola bien estrujada. 
tercera de águila ${ }^{26}$ y la cuarta de león sin garras ${ }^{27}$. Igualmente claro está el carácter hermafrodita del alboraique ${ }^{28}$. La silla que le monta es rica ${ }^{29}$, con su fuste de palo de higuera ${ }^{30}, \operatorname{los}$ estribos de metales diversos ${ }^{31}$, las riendas espadas y el freno de fuego ${ }^{32}$. Lo que la xilografía ya no recoge por ser monocroma, es el pelaje de todos los colores que caracterizaba a este animal mitológico ${ }^{33}$, ni tampoco que eran omnívoros ${ }^{34}$.

En el ejemplar escurialense encontramos una perfecta adecuación de la imagen y el texto, pero ignoramos si esa figura se repitió en pintura o escultura en el siglo XVI y entró a formar parte del repertorio figurativo de los artistas, o más bien fue el colofón de un odio y una guerra implacables desde el siglo XV. En este punto, lo que podemos constatar es que el alboraique fue de nuevo recreado en el siglo XVI, y es una imagen específicamente española. Vistos sus antecedentes, pudo haber sido Sevilla el lugar de su nueva elaboración, reforzándo-

${ }^{26}$ La xii una pierna de aguila con pie con uñas auia el alborayque. Assi los alboraycos biuen de rapiña robando las yglesias: comprando los obispados: canongias: et las otras dignidades de la madre sancta yglesia tomando ordines de clerigos: et no creen la sancta fe catholica: ni la missa que dizen. E assi en los recaudamientos et mayordomias que han poder de los reyes et señores de la tierra: dandoles quadernos desaforados: porque les pujan las rentas: et roban biudas et huerfanos et pobres et labradores con los ricos: levando de los derechos lo que pueden: et de los pobres mas de lo que deuen.

${ }^{27}$ La xiii condicion: pierna de leon sin uñas: la fortaleza del leon toda despues de la que ha en la boca ha en las uñas. E assi notorios es los judios que son captiuos et vendidos del tiempo de Titus et Vespasiano: en la destrucion de Ierusalen postrimera.... descienden del tribu de Juda que es llamado leon: ma no han no auran rey del dicho tribu de Juda: fasta la fin que se conuertiran al nuestro señor Jesu Cristo que es rey uniuersal que descendio del tribu de Juda.

${ }^{28}$ La xvi el alborayque no era macho ni hembra: mas tenia natura de macho et de fembra: la sodomia es venida de judios.... de los judios vino a los moros: et de los moros a los malos cristianos como Diego Arias etc. el qual fue principio et causa de la perdicion que sera fecha en España.

${ }^{29}$ La xvii la silla de un estrado rico: todo su proposito et fecho de los conuersos es auer riquezas temporales en este mundo: et no curan de las riquezas spirituales. Esto les viene por opinion antigua de sus parientes los judios: los quales nunca demandaron a Dios sino cosas temporales: pan vino azeyte etc.

${ }^{30}$ La xviii el fuste de la silla de palo de higuera. La xviii es el palo del fuste de la silla del alborayque que era de figuera. E esto es de notar que el fundamento de la creencia desta gente de los alboraycos sobre que estan sus opiniones asentadas es la sin[ag]oga que es la compaña de los judios que venieron despues de Cristo. E los que fueron en su muerte: la qual sin[ag]oga que quiere dezir finegoz que es antecristo no recibientes el verdadero messias que es Iesus: et recibiran al antecristo que verna lo qual es significado en aquella figuera que Iesu Cristo maldixo que nunca mas leuase fruto et secose de las rayzes fasta las hojas.

${ }^{31}$ La xix los estribos de muchos metales. Esto es que los alboraycos son de muchos metales: non solo en la conuersion: que unos fueron conuertidos por Cristo: et no permanecieron et su fe et ley ..... Los otros alboraycos fueron los que conuertio sant Pedro et los apostoles despues de las ascension de Cristo. E despues por dicho de Cayphas y otros principes dexaron la vida cristiana. Otros son de los tiempos modernos de quien el p[ro]logo: et se baptizaron por fuerça: et estos no son cristianos. E esto de deuen auer por reproche: los buenos de los conuersos de Castilla antes por honrra: que si ouiessen de ser juzgados con los conuersos andaluzes y aun tholedanos: todos serian condenados por malos hereges: lo qual no es assi mas lo contrario. Ca assi como en Castilla Vieja Burgos Palencia Valladolid Çamora Leon etc. apenas fallaran dellos de los conuersos naturales hereges ningunos. Assi en el reyno de Tholedo et Murcia et Andaluzia Estremadura apenas fallaredes dellos ningunos cristianos fieles: lo qual es notorio en toda España. Aunque la gran heregia destos quiere traer causa de durar en los otros de Castilla arriba.....

Concluyo si los metales son muchos en los alboraycos segund la carne. quanto mas de metales de tantas heregias como han et tienen de tiempos antiguos ..... et despues de las heregias que tienen de los infieles padres suyos que han venido mil et quatrocientos años ha: et mas captiuos ciegos entre los cristianos et moros.

${ }^{32}$ La xx el freno de fuego encendido: et las riendas de espada acicalada de acero fino. Esta gente si freno no le pusiessen sin rienda fueran a caer en mayores daños pero darles han una sofrenada: et seguir sea la muerte de espada cruel en ellos.

${ }^{33}$ La xiiii señal del alborayque el pelaje era de todas colores. A todas colores a todas maldades que fazen dan colores estos alboraycos: ca quando se fallan con los judios dizen judios somos. quando los cristianos dizen cristianos somos: han condiciones adoptadas a malas similitudines.

${ }^{34}$ La xv condicion del alborayque es: que come de todos manjares. Assi los alboraycos comen conejos perdizes muertas de manos de cristianos et de moros: et pescado que ellos comen poco tozino: liebres et otros animales et aues adafinas como judios et comenlo en todo tiempo: y en la quaresma de los cristianos: y en el ayudo de los judios: y en el ayuno de los moros: los mas dellos que pocos guardan las cerimonias de los otros. 
se con ello la hipótesis de Salvá, de que este libelo ilustrado es un producto salido de las prensas de J. Cromberger. Si abundando en lo mismo, colocamos a mediados de siglo el momento de la edición del opúsculo, podemos confirmar que el Alboraique aparece cuando el odio hacia los conversos ha triunfado en toda toda la línea en España, alcanzando su éxito más sonado el 23 de julio de 1547, cuando el Arzobispo Juan Martínez Silíceo impone, con apoyo de buena parte del Cabildo, los Estatutos de limpieza de sangre en la mismísima Catedral de Toledo.

La terrible amenaza expresada en el librito, «et seguir sea la muerte de espada cruel en ellos», iba poniéndose en práctica, fundiendo religión y racismo en esas peculiares figuras, tan españolas como el mismo alboraique, cuales fueron los cristianos viejos y los nuevos, último eslabón de una cadena de odios antiguos y encallecidos, que no tenía más horizonte que la división de los españoles y el exterminio del contrario en el nombre de Dios.

Agustín Bustamante García Universidad Autónoma de Madrid

\section{ARTISTAS DE LA CORTE DE LOS REYES CATÓLICOS EN ZARAGOZA *}

Las visitas de los Reyes Católicos - y de sus descendientes los Austrias del siglo XVI- a las diversas ciudades de los antiguos reinos peninsulares, suponían un encuentro de diferentes artífices pertenecientes a campos artísticos distintos. Unos, al estar al servicio de los monarcas eran «andantes en corte» y, por tanto, solían acompañarlos en sus desplazamientos, otros, se trasladaban a esas ciudades para coincidir con los monarcas y buscar obra o reclamar pagos atrasados, aprovechando que los comitentes más poderosos se daban cita en esos lugares concretos. Los artistas de fuera se relacionaban con los locales y fruto de estos encuentros era un fluido intercambio de ideas y modelos artísticos, sin olvidar, en esta difusión de novedades, el papel de las obras que traían los potentes magnates. Estos desplazamientos reales fueron, con frecuencia, una oportunidad para la innovación del arte de los lugares visitados, un aspecto que solemos olvidar, justificando los cambios formales, casi exclusivamente, por los viajes de nuestros artistas a Flandes en el siglo XV y a Italia en el siguiente.

Centrándonos en el antiguo reino de Aragón, conocemos la repercusión en la vida artística de Zaragoza de la visita del joven Carlos I (1518-1519), al darse cita en la capital del Ebro ${ }^{1}$, entre otros artífices, el escultor italiano Domenico Fancelli, el nórdico Felipe Bigarny, escultor afincado en Burgos y el castellano, pintor de su Alteza, Alonso Berruguete, recién llegado de Italia, que coinciden en la ciudad con el escultor valenciano Damián Forment, residente en la misma desde 1509, al hacerse cargo del monumental retablo del Pilar.

En esta ocasión retrocedemos de fecha y reyes, para situarnos a finales de mayo de 1498, cuando la corte española y la portuguesa llegan a tierras de Aragón. El 2 de junio hacía entrada solemne en Zaragoza el cortejo real, uno de los más majestuosos que recuerdan los fastos de nuestra ciudad. El fin primordial de esta visita era que la Infanta doña Isabel fuera jurada en las

\footnotetext{
* El trabajo se ha realizado con parte del Apoyo a la Investigación de la Universidad de Zaragoza.

' C. Morte, «Carlos I y los artistas de Corte en Zaragoza: Fancelli, Berruguete y Bigarny», Archivo Español de Arte, 255 (1991), págs. 317-366.
} 